\section{Malignant Acanthosis nigricans associated with early diagnosis of liver cancer*}

João Roberto Antonio, ${ }^{1,2}$

Lívia Arroyo Trídico ${ }^{2}$

Carlos Roberto Antonio ${ }^{1,2}$

DOI: http:/ /dx.doi.org/10.1590/abd1806-4841.20187560

Dear editor,

Acanthosis nigricans is a skin condition characterized by symmetrical hyperpigmented, velvety, papillomatous plaques that tend to affect flexural and intertriginous areas, although it can affect any part of the body. The diagnosis of acanthosis nigricans is based on the clinical aspect of the lesions and can be classified into benign or malignant. The former is the most common and is usually associated to endocrinological disorders (type 2 diabetes, acromegaly, Cushing syndrome, hypothyroidism and insulin resistance), as well as congenital abnormalities or drugs. ${ }^{1}$ The malignant form is associated to internal neoplasms. ${ }^{2}$

Malignant acanthosis nigricans was first described in 1890 by Pollitzer, who noted an association with a gastrointestinal tumor. ${ }^{3}$ It is characterized as a paraneoplastic skin condition of intra-abdominal malignancies and, contrary to benign acanthosis nigricans, it has a sudden onset, rapid course and extensive skin involvement. Its etiology is associated to tumor-produced substances that stimulate keratinocytes, melanocytes and fibroblasts, being transforming growth factor (TGF- $\alpha$ ) the main substance involved because it acts in the epidermis through the epidermal growth factor receptor (EGF-1). ${ }^{4}$

Even though the neoplasm most frequently associated to acanthosis nigricans is gastric adenocarcinoma (56-61\%), associations with ovarian, endometrium, cervix, breast, testicle, lung,

Received 20 August 2017.

Accepted 26 November 2017.

* Work conducted at clínica Pelle, São José do Rio Preto (SP), Brazil.

Financial support: None.

Conflict of Interests: None.

1 Discipline of Dermatology, Faculdade de Medicina de São José do Rio Preto, São José do Rio Preto (SP), Brazil.

2 Service of Dermatology, Hospital de Base de São José do Rio Preto, São José do Rio Preto (SP), Brazil.

MAILING AdDRESS:

Lívia Arroyo Trídico

E-mail: latridico@gmail.com

(C)2018 by Anais Brasileiros de Dermatologia kidney, pancreatic, liver, esophagus, prostate, thyroid, pharynx carcinoma, among other, were already described. ${ }^{5}$ The malignancy can be identified before, during or after the onset of skin lesions. ${ }^{5}$ In most cases, they occur concomitantly (61.3\%), however, in $17.6 \%$ of cases, the lesions occur before the malignancy and in $21 \%$ of cases, after the tumor is identified. ${ }^{4}$ We report the case of a patient with malignant acanthosis nigricans that preceded the diagnosis of the neoplasm, contributing to the early diagnosis of the tumor.

Female 53-year-old patient presented with the complaint of a 5-month history of progressive brown, isolated lesions on her skin located on the axillae, between her breasts, back, buttocks and internal aspect of the thighs. The patient also complained of malaise for 1 month.

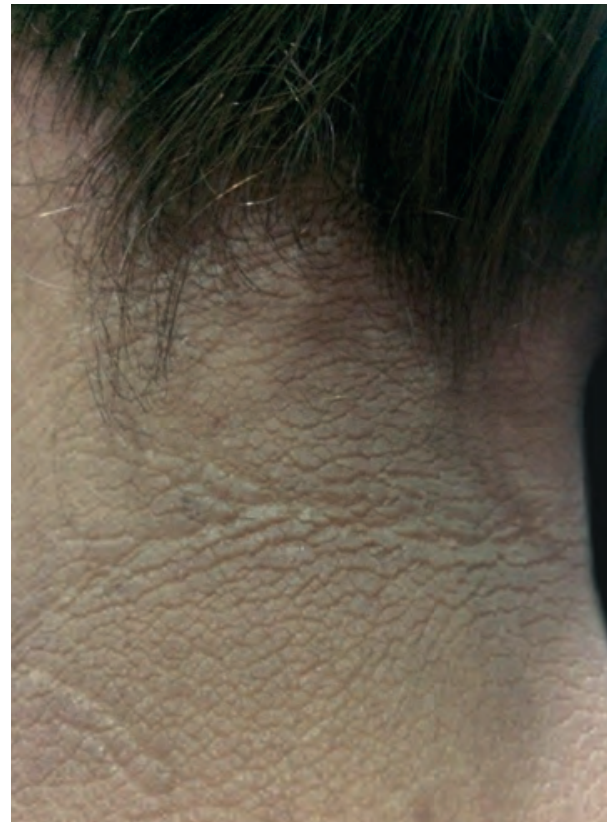

Figure 1:

Acanthosis nigricans on the neck

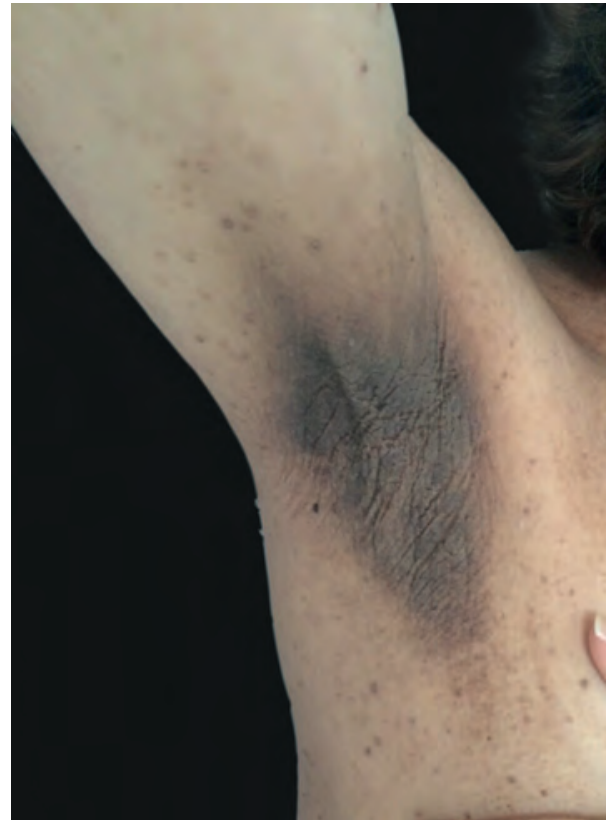

FIGURE 2:

Acanthosis nigricans on the axillae 


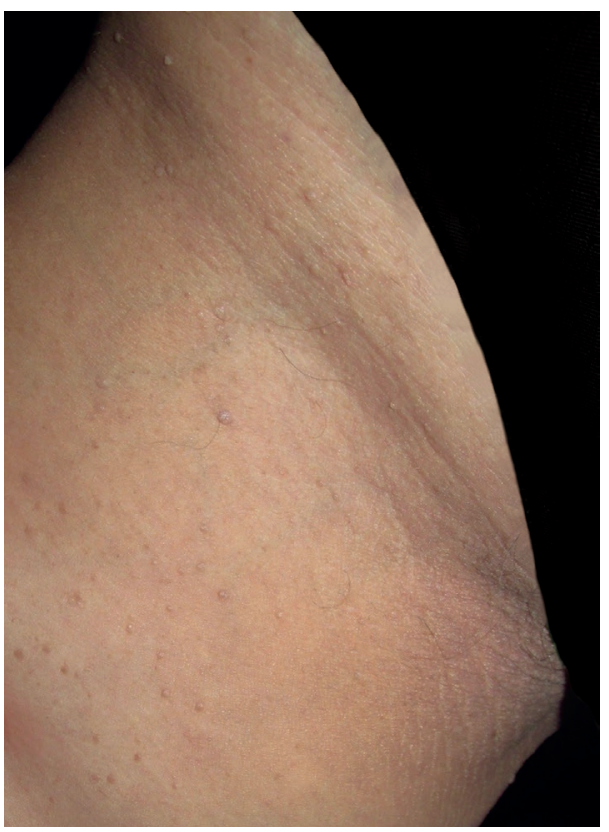

Figure 3:

Acanthosis nigricans on the medial thigh

Physical examination revealed hyperpigmented, hyperkeratotic verrucous plaques distributed on the axillae, intermammary region dorsum, nape of the neck, postauricular region and buttocks, and subtler lesions on the medial aspect of the thighs, with clinical features of acanthosis nigricans (Figures 1 to 3 ).

We requested pathology and imaging to investigate likely paraneoplastic syndrome. On the magnetic resonance imaging, an expansive lesion in the liver was identified (segment VII), measuring $7.0 \times 6.6 \times 4.8 \mathrm{~cm}$, with signs of right hepatic vein invasion and inferior vena cava compression, probably hepatocellular in origin. The patient underwent biopsy of the liver mass and after immunohistochemistry, the diagnosis of infiltrative adenocarcinoma with likely primary site in the com pancreatic and biliary tract (intra or extrahepatic bile ducts or pancreas) was made.

The patient underwent a delicate surgical treatment due to the location (right hepatectomy), however successful, followed by chemotherapy. After surgical treatment of the malignancy, the cutaneous lesions started to resolve, with complete resolution after four months. At the moment, the patient is clinically cured of the neoplasm and has no acanthosis nigricans lesions.

The prognosis of patients with cancer and acanthosis nigricans is poor, for it is usually a high-grade neoplasm associated to metastases. Malignant forms can be clinically indistinguishable from benign acanthosis nigricans, therefore, a good history taking is essential to investigate cases of rapid onset and a thorough physical examination is needed to evaluate the involvement of uncommon regions and extensive locations.

In the described case, we made an early diagnosis of an aggressive liver cancer in a dangerous location. Cure was possible due to fast therapeutic intervention. The most important signs suspicious for paraneoplastic syndrome included age, the sudden onset of the lesions, ongoing progression, involvement of extensive areas and absence of endocrinological abnormalities on screening tests.
In our case, the cancer associated to acanthosis nigricans was hepatocellular in origin, uncommon in cases of malignant acanthosis nigricans. Another important information was that the skin lesions preceded the neoplastic manifestations, what was essential for an early diagnosis and cure of the neoplasm and the skin lesions. It is known that surgical or chemotherapeutic treatment of the tumor is associated to improvement of malignant acanthosis nigricans while dissemination of the lesions can occur when the neoplasm metastatizes. $^{2}$ ]

\section{REFERENCES}

1. Schwartz RA, Janniger EJ. Acanthosis nigricans - a common significant disorder usually unassociated with malignancy. Przegl Dermatol. 2011,98:1-6.

2. Brinca A, Cardoso JC, Brites MM, Tellechea 0, Figueiredo A. Florid cutaneous papillomatosis and acanthosis nigricans maligna revealing gastric adenocarcinoma. An Bras Dermatol 2011;86:573-7.

3. Pollitzer S. Acanthosis nigricans. In: Unna PG, Morris M, Besnier E, Duhring LA, editors. International atlas of rare skin disease. London: HK Lewis \& Company; 1890. p. 1-3.

4. Kubicka-Wołkowska J, Dębska-Szmich S, Lisik-Habib M, Noweta M, Potemski P. Malignant acanthosis nigricans associated with prostate cancer: a case report. BMC Urol. 2014;14:88.

5. Rigel DS, Jacobs MI. Malignant acantosis nigricans: a review. J Dermatol Surg Oncol. 1980;6:923-7.

\footnotetext{
AUTHORS CONTRIBUTION

João Roberto Antonio

ORCID 0000-0002-0268-5934

Obtaining, analyzing and interpreting the data; Effective participation in research orientation; Intellectual participation in propaedeutic and/or therapeutic conduct of cases studied; Critical review of the manuscript

Lívia Arroyo Trídico

ORCID 0000-0002-7743-4195

Elaboration and writing of the manuscript; Critical review of the literature

Carlos Roberto Antonio

ORCID 0000-0001-9243-8293

Intellectual participation in propaedeutic and/or therapeutic conduct of cases studied
}

How to cite this article: Antonio JR, Trídico LA, Antonio CR. Malignant Acanthosis Nigricans associated with early diagnosis of liver cancer. An Bras Dermatol. 2018:93(4):616-7. 